\title{
Opposing actions of STAT-1 and STAT-3 on the Bcl-2 and Bcl-x promoters
}

\section{Dear Editor,}

The Bcl-2 family of proteins contains at least 15 members which can have pro- or anti-apoptotic effects. All share at least one of four Bcl-2 homology domains (BH1 to $\mathrm{BH} 4)$, and inclusion of different $\mathrm{BH}$ domains in individual $\mathrm{Bcl}-2$ family members is generally responsible for pro- or anti-apoptotic activity (reviewed in ${ }^{1}$ ). Pro- and anti-apoptotic members can form heterodimers, and their ratio may determine whether a death or survival signal is delivered. ${ }^{2}$ There is strong evidence that the actions of $\mathrm{Bcl}-2$ proteins are exerted at the level of the mitochondrial membrane (reviewed $\mathrm{in}^{3}$ ). Thus many $\mathrm{Bcl}-2$ members are anchored in the mitochondrial outer membrane, and anti-apoptotic family members such as $\mathrm{Bcl}-2$ and $\mathrm{Bcl}-\mathrm{X}_{\mathrm{L}}$ form ion channels which increase the rate of proton extrusion from mitochondria.

Some studies have begun to address the transcriptional regulation of anti-apoptotic $\mathrm{BCl}-2$ genes. In leukaemias, for example, a hybrid transcription factor formed by chromosomal rearrangement increases $\mathrm{Bcl}-2$ expression, ${ }^{4}$ and overexpression of the CCAAT enhancer binding protein, GADD153, reduces Bcl-2 expression with an accompany-

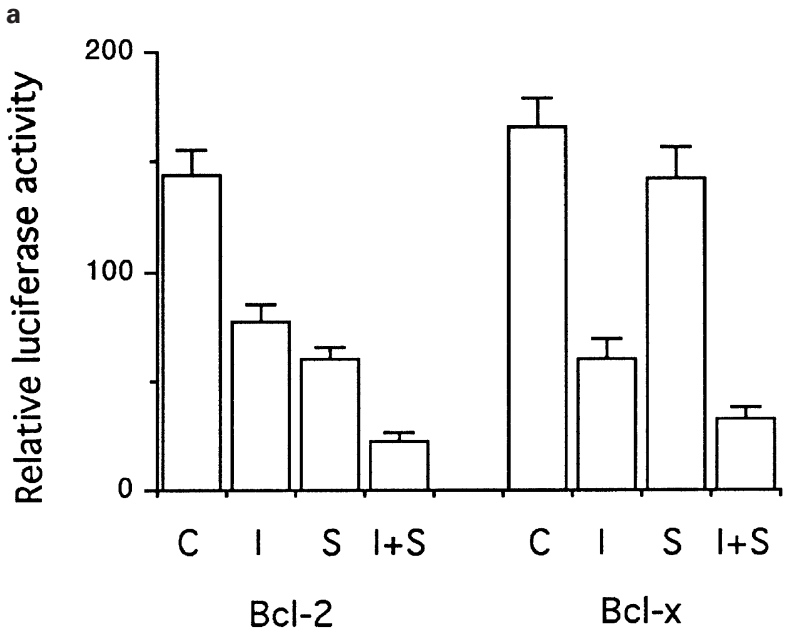

b
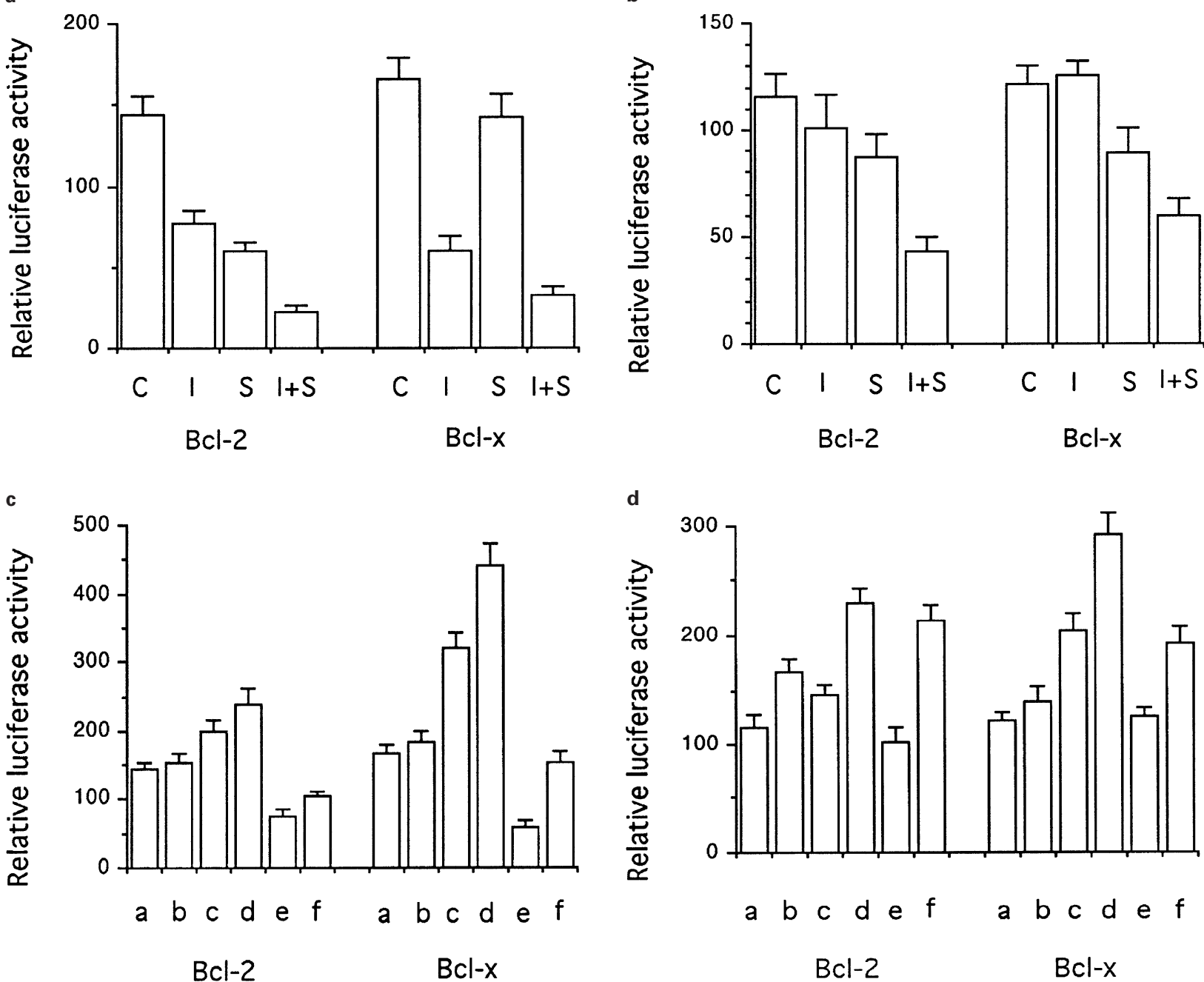

d

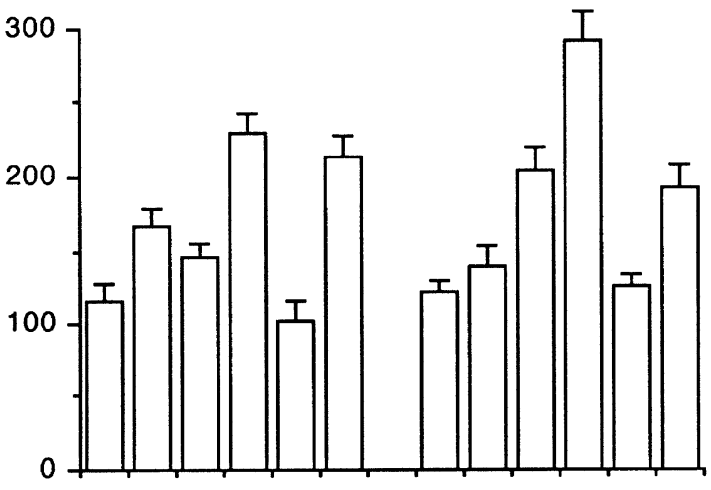

a b c d e f a b c d e f

$\mathrm{Bcl}-2$

$\mathrm{BCl}-\mathrm{x}$

Figure 1 Effects of IFN $\gamma($ I), STAT-1 (S) and both IFN $\gamma$ and STAT-1 (I+S) on control (C) basal activity of the Bcl-2 and Bcl-x promoters in STAT-1 expressing (a) and STAT-1 deficient (b) U3A cells. Effects of CT-1 and STAT-3 on basal activity of the Bcl-2 and Bcl-x promoters in STAT-1 expressing (c) and STAT-1 deficient (d) U3A cells. a: control basal activity; b: STAT-3; c: CT-1, d: CT-1+STAT-3; e: IFN $\gamma$; f: IFN $\gamma+C T-1$ 
ing increase in apoptosis. ${ }^{5}$ In neuronal cells, transactivation of Bcl-2 by the POU factor, Brn-3a, is inhibited by p53, although $\mathrm{p} 53$ itself has little effect on basal $\mathrm{Bcl}-2$ expression. ${ }^{6} \mathrm{NF}-\kappa \mathrm{B}$-dependent enhancement of $\mathrm{BCl}-\mathrm{x}_{\mathrm{L}}$ expression has been reported to mediate survival signals transduced through CD40 in B cells, ${ }^{7}$ and the transcriptional repressor, Btf, which induces apoptosis, is normally retained in the cytoplasm by $\mathrm{Bcl}-2$ and $\mathrm{Bcl}-\mathrm{x}_{\mathrm{L}} \cdot{ }^{8}$

In the heart, there is also evidence that apoptosis following ischaemia/reperfusion (IR) injury is associated with modulation of $\mathrm{Bcl}-2$ and $\mathrm{Bcl}-\mathrm{x}_{\mathrm{L}}$ expression. For example, in the isolated perfused rat heart, IR reduces $\mathrm{Bcl}-2$ expression, in parallel with increased AP-1 and reduced $\mathrm{NF}-\kappa \mathrm{B} .^{9}$ Moreover, the reduction in apoptosis in IR rabbit hearts produced by phenylephrine preconditioning is associated with an increased Bcl-x/Bax ratio. ${ }^{10}$ Since we have observed that activated Signal Transducer and Activator of Transcription (STAT)-1 is an important transactivator in the apoptosis induced by IR injury, ${ }^{11}$ and others have shown that STAT-3 is involved in the cardioprotective actions of cardiotrophin-1 (CT-1), ${ }^{12}$ we have studied whether these pro- and anti-apoptotic effects of STATs- 1 and 3 are mediated by regulation of the expression of the $\mathrm{Bcl}-2$ and $\mathrm{Bcl}-\mathrm{x}_{\mathrm{L}}$ genes.

In U3A-ST1 cells constitutively expressing STAT-1 (Figure 1a), IFN $\gamma$, a known activator of STAT-1, reduces basal expression of the Bcl-2 promoter. Transfection with STAT- 1 by itself also reduces Bcl-2 promoter activity and overexpression of STAT-1 together with IFN $\gamma$ treatment produces a reduction significantly greater than by either STAT-1 or IFN $\gamma$ alone. This presumably reflects phosphorylation of transfected STAT-1 by Janus kinases activated by ligation of the IFN $\gamma$ receptor. Figure 1a also shows that $\mathrm{IFN} \gamma$ reduces basal activity of the Bcl-x promoter; although the reduction in $\mathrm{Bcl}-\mathrm{x}$ promoter activity produced by STAT-1 overexpression alone is less pronounced than with the Bcl2 promoter, it is still significant, and IFN $\gamma$ treatment of STAT-1 overexpressing cells again results in more profound reduction in Bcl-x promoter activity than IFN $\gamma$ or STAT- 1 alone. The reduction by IFN $\gamma$ in $\mathrm{Bcl}-2$ and $\mathrm{Bcl}-\mathrm{x}$ promoter activity is not seen in the STAT-1 deficient cell line U3A, indicating that it is dependent on activation of STAT-1. Moreover, expressing STAT-1 alone or together with IFN $\gamma$ treatment does reduce activity of both promoters, indicating that the effect of IFN $\gamma$ can be restored by expressing STAT-1 in the STAT-1 deficient cells (Figure 1b).
Figure 1c shows that CT-1, a STAT-3 activator, can enhance $\mathrm{Bcl}-2$ and $\mathrm{Bcl}-\mathrm{x}$ activity. Moreover, $\mathrm{CT}-1$ reverses the suppressive effect of IFN $\gamma$ on the $\mathrm{Bcl}-2$ and $\mathrm{Bcl}-\mathrm{x}$ promoters (Figure 1c, bars e and f), most markedly in the STAT-1 deficient cell line (Figure 1d). In the STAT-1 deficient cells, both STAT-3 and CT-1 individually enhance $\mathrm{Bcl}-2$ and $\mathrm{Bcl}-\mathrm{x}$ promoter activity, and $\mathrm{CT}-1$ also has this effect in STAT-1 expressing cells. The combined effects of STAT-3 and CT-1 are again greater than either factor alone.

The data suggest that one mechanism by which STAT-1 mediates IR-induced apoptosis is by reducing expression of anti-apoptotic $\mathrm{Bcl}-2$ and $\mathrm{Bcl}-\mathrm{x}$ genes. In addition, the cardioprotective effects of CT-1 may be mediated by STAT-3 induced increases in expression of these genes. STAT-1 and STAT-3 homodimers activate distinct sets of genes. In addition, STAT-1 and STAT-3 can also form heterodimers. $^{13}$ The results reported here suggest that, in the heart, the relative proportions of STAT-1 and STAT-3 may affect the transcriptional activity of two anti-apoptotic genes. It is unclear whether STAT- 1 and STAT-3 act at a single site to regulate the $\mathrm{Bcl}-2$ and $\mathrm{Bcl}-\mathrm{x}$ promoters, or whether interaction between separate binding regions is involved. Promoter mapping studies are in progress to resolve this question.

\section{A Stephanou ${ }^{*, 1}$, BK Brar ${ }^{1}$, RA Knight ${ }^{2}$ and DS Latchman ${ }^{1}$}

${ }^{1}$ Molecular Medicine Unit, Institute of Child Health, 30 Guilford Street, London WC1N 1EH; ${ }^{2}$ Department of Cystic Fibrosis, Imperial College at the NHLI, Manresa Road, London SW3

${ }^{*}$ Corresponding author: Molecular Medicine Unit, Institute of Child Health, 30 Guilford Street, London WC1N 1EH. Tel: +44 171504 9207; Fax: +44 171373 3310; E-mail: anastasis_stephanou@Yahoo.com

1. Adams JM and Cory S (1998) Science 281: 1322-1326

2. Oltvai ZN et al. (1993) Cell 74: 609-619

3. Green DR and Reed JC (1998) Science 281: 1309-1312

4. Klampfer L et al. (1996) Proc. Natl. Acad. Sci. USA 93: 14059-14064

5. Matsumoto M et al. (1996) FEBS Lett. 395: 143-147

6. Budhram-Mahadeo V et al. (1999) J. Biol. Chem. 274: 15237-15244

7. Lee HH et al. (1999) Proc. Natl. Acad. Sci. USA 96: 9136-9141

8. Kasof GM et al. (1999) Mol. Cell. Biol. 19: 4390-4404

9. Maulik N et al. (1999) FEBS Lett. 443: 331-336

10. Baghelai K et al. (1999) J. Thor. Cardiovasc. Surg. 117: 980-986

11. Stephanou A et al. (2000) J. Biol. Chem, in press

12. Sheng Z et al. (1997) J. Biol. Chem. 272: 5783-5791

13. Ihle JN (1996) Cell 84: 331 - 334 